\title{
1. Analysing inequality and disadvantage from a capability perspective $^{1}$
}

\section{Jean-Michel Bonvin, Benoît Beuret and Stephan Dahmen}

The concept of (in-)equality is ambivalent and can be interpreted in a great variety of ways. As Sen has pointed out, all political and moral traditions since the Enlightenment are based on a conception of 'equality of something'. Even if equality is deeply enshrined in the discourse on modernity and intimately bound with the historical development of democracy, this 'something' varies from an author to another one, involving different conceptions of justice. Public action against inequalities is necessarily based on (implicit and explicit) judgements about existing disparities, some of them being assessed as illegitimate and therefore requiring a corrective intervention, other ones not. We argue that the question 'Equality of what?' (Sen 1979) is of central importance, as it also indicates what should be equalized and what can remain unequal. What inequalities require public intervention and why? Who decides about this and who is not involved in this identification of unacceptable inequalities? Our contribution aims at describing how a capability perspective on social inequalities allows tackling the complex interaction between inequalities, democracy and barriers to participation. Sections 1 to 4 emphasize the complexity of the issue of (in-) equality and the various conceptions in this field. Section 5 shows to what extent participation can make a difference when identifying and tackling inequalities. Section 6 concludes.

\section{FUNCTIONAL INEQUALITIES: A SOCIOLOGICAL VERSION OF 'FAIR' INEQUALITIES}

In the everyday life, people do not always associate interindividual disparities or unequal treatment with social inequality or injustice, even when especially offending for themselves. Studies in social psychology have 
confirmed that in specific contexts, subjects develop justifications that lead to 'see justice itself in social inequality' (Duru-Bellat 2011, p. 186). For understanding why inequalities may very well be perceived as 'fair' (and not only by members of the most privileged groups), such studies have provided various theories, claiming in particular that "the belief in a just world' (Dalbert 2001, p. 2) corresponds to a kind of cognitive need.

In sociology, this idea according to which substantial interindividual or inter-group disparities may be perceived as 'fair' has been subject to various interpretations. While critical traditions have mostly focused on the notion of 'ideology' (Gramsci, Foucault) or 'illusio' (Bourdieu), conceived as a mean for dominant groups to maintain their privileges without necessarily having to use physical violence, the functionalist paradigm insists, by contrast, on what we could call 'the hypothesis of necessity'. Its theoretical foundations explain why some disparities may be collectively perceived as 'fair', 'just' or even 'natural'.

Following Durkheim's ([1893] 1973) famous model of 'organic society', modern forms of social organization are intimately bound with work division. Due to mechanisms of specialization, work division generates a great heterogeneity of social positions: like the tissues of organs, interindividual collaboration performs specific functions, whose complementarity ensures society's adequate functioning and development. Drawing on this 'organism metaphor' (Levine 1995), the Durkheimian society 'naturally' produces diversifications of positions and, one could argue, needs them for guaranteeing its prosperity and sustainability. As a consequence, disparities of class income and occupational status, as well as asymmetries of power between men and women, are considered as functional inequalities inherent to the social division of work.

While incorporating its basic assumptions on social systems, the American tradition of functionalism has complexified Durkheim's conception of functional inequalities. A pervading feature in Parsons' work is that structural asymmetries are legitimated by cultural norms and supported by a vast moral ranking system:

Social stratification is regarded here as the differential ranking of the human individuals who compose a given social system and their treatment as superior and inferior relative to one another in certain socially important respects. Our first task is to discuss why such differential ranking is considered a really fundamental phenomenon of social systems and what are the respects in which such ranking is important. (Parsons 1940, p. 841)

For our discussion, the most relevant fact is that both Durkheim and Parsons capture human hierarchies and disparities as consubstantial with social organization. Envisaged as a consequence of the heterogeneity of 
roles and functions, differences in life conditions appear to be irremediable, all the more so that contesting voices and behaviours are subject to sanctions inflicted by powerful institutions of social control (schools, prisons, hospitals). The subtlety of the functionalist conception lies in the fact that functional inequalities are not incompatible with a principle of equality between individuals. Indeed, what we would call nowadays 'equality of opportunity' represents the theoretical counterpart of functional inequalities and the precondition of social mobility, conceived as the main mean to overcome social divisions. For equality of opportunity to be effective, demands are expressed in order to secure what Durkheim calls 'the equality in the external conditions of struggle' (1973, p.371), namely by eliminating the impact of inherited privileges and emphasizing the sole individual merit. The theoretical legacy of functionalism implies thus a strong complementarity between functional inequalities and a policy of 'equality of opportunities' based on individual merit. If such equality of opportunities is guaranteed, differential outcomes are seen as legitimate.

At a theoretical level, two interrelated critiques can be formulated. First, functionalist analyses remain too much captive of the concept of 'integration', which leads to an overvaluation and reification of the social order. Slavery, to take a quite extreme example, is not incompatible with functional integration. On the contrary, one can ask what is more 'integrated' than a slave whose body and soul fully belong to his/her master? From a conflict-theory point of view, the integration paradigm deflects sociological attention from mechanisms of domination that produce inequalities, and thus incurs the risk of 'naturalizing' structural inequalities. Second, asserting the existence of irreducible inequalities can be seen per se as a mode of exercising power along the cognitive dimension, which in turn sets severe limits to what can realistically be changed by political means. Indeed, accepting the functional requirement hypothesis dramatically restrains the scope of political action. We argue that such a conception of inequalities risks resulting in a fatalist notion of public action which restricts itself to the integration of beneficiaries within a pre-given and undisputable social order.

\section{IDENTIFYING THE MULTIDIMENSIONAL AND CUMULATIVE CHARACTER OF INEQUALITIES}

Since these pioneering studies, the sociological literature has stressed the complexity of inequality and the various forms it can assume. These arise first and foremost from the multiple angles through which inequality can be grasped and documented. While research focusing on categories 
of actors (according to their occupation, race, gender, age, religion, geographical or social origin and so on) or inequality criteria (income level, health status, social capital, mortality, wealth and so on) identify substantial disparities, other approaches move away from such strictly descriptive perspectives to concentrate on socialization factors (family, peers, school, work environment and so on), thus privileging an understanding of the processes by which inequalities are created, maintained or reinforced. From a similar perspective, qualitative approaches have demonstrated the crucial role of immaterial resources like social and cultural capital. In the realm of education, famous studies have found that school not only fails to annihilate the effect of social origin but sometimes increases social class disparities. Beside institutional or organizational factors like segmentation of schooling pathways or racial and class homogeneity of school populations, scholars insist on the significant role played by educational codes, the 'habitus' of teachers or a pupil's family school choices. These aspects, hardly measurable and often remaining invisible when using quantitative methods, may all the same represent strong barriers to equal opportunity in education and training, with strong effects on social mobility. 'Descriptive' and 'explicative' approaches to inequality are both useful and should be considered as complementary. However, some scholars have recently underlined that the former may result in an unending collection of inequalities, which could lead to a kind of undertheorized 'social botanics' (Dubet 2011, p. 4).

These few examples highlight the need for a conceptual framing of inequality in terms of cumulativity. Basically, this includes those mechanisms which confront individuals, both at a synchronic and diachronic level, to cumulative (dis-)advantages. In this respect, the realm of health illustrates with particular strength the interplay between social origin, educational level, living and working conditions, health behaviours and health conditions (for example, Marmot and Wilkinson 2005). For an understanding of cumulative effects, Bourdieu's (1966) theory of interlocking capitals and 'class habitus' offers a powerful general framework. Quite recently, life-course approaches have included longitudinal perspectives, paying attention to the very mechanisms by which initial differences transform over time into comparative (in-) equalities that increase the gaps between groups, in terms of lived experiences, opportunities and achievement. They have offered convincing evidence against common conceptions of misfortune or 'biological programming', highlighting not only the role of social factors in the occurrence of illness but also its differential outcome on individual trajectories according to social capital and available resources. However, as Graham (2004, p. 101) puts it, 'the social factors promoting and undermining the health of individuals and populations should not 
be confused with the social processes underlying their unequal distribution'. Thus, another important point in relation to cumulativity concerns the unequal distribution of particular life-events that can affect other life spheres. For example, while unemployment is often presented as a risk factor for health (Dooley, Fielding and Levi 1996; Kessler, Turner and House 1988), especially when it lasts over a certain duration, its distribution (that is, the risk to face long-term unemployment) is obviously not independent from such variables as age, gender, race or educational level. Long-term analyses of life chances, health, or self-reported well-being demonstrate the importance of taking the 'long view' when studying inequality, because past experiences contribute to shape present and future life opportunities, but also because some risks lead to immediate effects, while others take considerable time to become manifest.

The concept of intersectionality is also a significant contribution in this field. It finds its origin in the development of Black feminism during the 1970s and 1980s, which criticized 'mainstream' (that is, white and middle class) feminism for insufficient consideration of race in the analysis of women's structural and historical domination. Leading scholars on intersectionality insist on the need to challenge domination and inequality but, unlike the feminist tradition, not solely or necessarily as gendered subjects but as 'women whose lives are affected by their location in multiple hierarchies' (Zinn and Dill 1996, p. 321). Drawing on Hochschild's (1983) seminal masterwork, studies focusing on child- and eldercare in Western societies have reconsidered issues of equality/inequality in relation to the ever growing delegation of carework to women from poor countries of subsaharan Africa, Asia and Latin America (Duffy 2007; Glenn 2000, 2010; Ibos 2013; Parreñas 2000). While some women, mostly white, delegate a part of the domestic work in order to recover a job and gain autonomy vis-à-vis their husband or men in general, other women, mostly non-white, leave their young children and elder parents to care for others in occidental countries. The massive hiring of non-white 'nannies' and careworkers in the context of 'transnational care economies' (Ibos 2009, p. 123) thus entails obvious racial dynamics, whose meanings deeply call into question the vision of (or claim for) women's empowerment.

By bringing back racial issues and in particular 'the Black women's standpoint' (Collins 1990, p. 16) in Gender studies, intersectional approaches have contributed to reconfigure the cartography of feminist research and feminist movements. Focusing on the daily life of marginalized women of colour, intersectional perspectives tend to refute all models that postulate a priori hierarchies between gender, class or racial inequalities, arguing that women often experience all of them simultaneously, though in different ways and along various configurations. Priorities within mainstream 
feminism have been thus refocused via attention to existing differences between women's positions inside what Collins (1990, p. 225) calls a 'matrix of domination'. From this perspective, people of the same race will, for example, experience race differently depending upon their location in the class structure (as employed or unemployed, as production worker or professional manager and so on). Despite political and methodological heterodoxy, studies on intersectionality have produced insightful analyses on inter-group disparities of wealth, power and privilege by articulating various social locations (especially race, gender, class and sexual orientation) and proposing diverse ways of understanding inequalities in practice (Choo and Ferree 2010).

The cumulative, multidimensional and intersectional character of social inequality, as well as its differential impact over time, thus highlights the crucial role of what Sen calls the informational basis of judgement in justice' (IBJJ) (Sen 1990, p. 111). Insisting on the fact that all individual or social judgements rest on a specific set of information (hence implying the corollary exclusion of all other information), the notion of IBJJ draws the attention to the selection of sources and indicators through which social problems are defined, that is, the way inequalities are rendered visible and measurable. In other words, when identifying inequality, some dimensions are emphasized while others are discarded. This cognitive framing of the problem has in turn great influence on the solutions proposed, that is, the way public action is designed to address the problem. The issue, then, is to assess whether and to what extent the informational basis of public policies takes account of the intersectionality and cumulativity of social inequalities.

\section{CONTESTING FUNCTIONAL INEQUALITIES: THE IMPORTANCE OF SOCIAL MOVEMENTS}

Drawing on studies focusing on the notion of disadvantage, one can find particular insights to re-specify the question of inequality and take account of the role of social movements in winning acceptance of alternative definitions of a problem. Historically, this concept is closely bound with the development of Disability studies, a research programme born in the wake of collective efforts conducted since the 1970s by activists, scholars and organizations to improve the inclusion of disabled people and tackle the supremacy of the medical discourse in the realm of disability. The critiques of disability scholarship are based upon two main arguments. On a scientific (knowledge-related) level, the medical paradigm fails to grasp adequately - and often merely ignores - the experiences and narratives of 
people concerned with disability issues (Barnes, Mercer and Shakespeare 1999; Oliver 1990; Thomas 1999). On a political (normative) level, it systematically privileges curative and rehabilitative policies, which de facto foster segregation and dependency of physically and mentally impaired people vis-à-vis non-disabled people (Albrecht 1992; Hahn 1982). While physicians and rehab professionals used to - and to a large extent they still do it - locate the problem within the individual, thus considering disability as a personal tragedy and normalization as the ultimate goal of public action, Disability studies restores the viewpoint of disabled people by formulating a 'social model' emphasizing the role of the social, political and cultural context in disablement processes (Shakespeare and Watson 1997).

The notion of disadvantage appears as the cornerstone of this reconceptualization: for a similar impairment, one can result very disadvantaged, that is, very limited in his/her functionings, while another one succeeds in living the life s/he has reason to value. In other words, the concept of disadvantage refutes any mechanical correspondence between impairment and disability, insisting on the fact that issues of disability are not just questions of organic disruptions, functional limitations, or psychological disorders, but issues of local settings, administrative categorizations, and political will. This emphasizes the necessity to consider disadvantage at the crossroad of individual and social factors, both to be envisaged in a contextualized and situated way. This model raises issues of generalization insofar as it focuses on 'requirements of justice and equality' (Zimmermann 2006, p. 471) for physically or mentally impaired persons, but at the same time it points out the relevance of singularity, highlighting contrasted experiences and concerns, as well as variable contexts and functionings.

One can find similar tensions between generality and singularity in Wolff and de-Shalit's (2007) book. Building on a pluralist conception, these authors define disadvantage in terms of 'a lack of genuine opportunities for secure functionings' (Wolff and de-Shalit 2007, p. 182). Linking issues of disadvantage and social justice, they insist particularly on the necessity to eradicate what they call 'corrosive disadvantage', that is, 'disadvantage in one functioning that leads to disadvantages in others' (Wolff and de-Shalit 2007, p. 133). By contrast, some functionings are deemed to be 'fertile' and have to be encouraged, because they can favour other functionings: 'doing well in one functioning . . . will lead to improvements in other functionings' (Wolff and de-Shalit 2007, pp. 133-134). The notion of disadvantage thus emphasizes that inequality cannot be detached from the processes and contexts within which it becomes practically significant in terms of functionings and opportunity sets. For this specific reason, general knowledge supplied by social scientists, experts or administrators cannot obliterate the practical knowledge of 'insiders'. 
At an ethical and methodological level, this implies a particularly demanding politics of inquiry, similar to the one developed by Fraser (1987) in her politics of needs interpretation, which requires minimally a double commitment from the researchers, namely as scientists and as citizens. Consequently, disability scholars have pleaded for a strong orientation towards 'emancipatory research', in such a way that disabled people can reap the benefits of the inquiry to improve their situation and capabilities:

Emancipatory research is about the systematic demystification of the structures and processes which create disability, and the establishment of a workable 'dialogue' between the research community and disabled people in order to facilitate the latter's empowerment. To do this researchers must learn how to put their knowledge and skills at the disposal of disabled people. (Barnes 1992, p. 122)

Such an approach can be suitable for questioning the symbolic framing of issues with which public action is dealing. Instead of confining disability within a medical and rehabilitative approach, a 'social model' perspective based on the lived experiences of concerned persons paves the way for initiatives geared towards alleviating the structural barriers to inclusion, contesting dominant oppressive representations and promoting inalienable rights instead of public pity (Shapiro 1994). The contestation of categories and ascribed identities through such an emancipatory stance has serious implications for public policy and practice. Indeed, when disabled people internationally claim 'nothing about us without us', they do not reclaim anything else than unconditional participation to choose for themselves, which highlights the crucial importance of a participative orientation when selecting the IBJJ of inequality or disadvantage.

\section{INEQUALITIES AND PARTICIPATION: A COMPLEX INTERACTION}

A perspective which includes the subject's experience for emancipatory research and acknowledges the value of the situated knowledge of 'ordinary' persons, calls for a sophisticated concept of participation. This cannot be restricted to a formal voting process, in which citizens select the 'elites' by which they will be governed. More ambitious definitions of democracy see it intimately linked to processes of 'public deliberation'. According to Dewey, democracy takes the form of a collective 'social inquiry' where experiences are mediated through public discussion, and in which citizens engage into a collective learning process. Such a process 
can be defined as a method of 'organized intelligence' in which conflicts of interest are brought 'out into the open where their special claims can be discussed and judged in the light of more inclusive interests' (Dewey 1999, p. 56). Unlike minimalist theories of democracy, participation is not limited to formal political institutions, but applies in every arena where collective issues emerge in relation to people's experiences and concerns. Such a deliberation enhances the probability of taking into consideration hitherto neglected or invisible opinions and allowing the people concerned to participate effectively in all normative and rule-setting processes.

Undoubtedly, this is a demanding perspective, both in its preconditions and in its procedural requirements. Indeed, there is reason to believe that participation and inequalities (both material and symbolic) may often take the form of a vicious circle: 'an excluded group can overcome its exclusion only by initiating public deliberation, precisely what exclusion makes more and more difficult' (Bohman 1996, pp. 124-125). In addition, there is little guarantee that latent forms of power and coercion can be cancelled out in deliberative arrangements, especially if these are solely based on notions of 'formal' equality before the law and on procedural guarantees. Many studies have shown that despite formal equality, people from different social milieus have unequal chances to make their voice count and exercise their participation rights. Exploring the access of young adults facing multiple difficulties in a French urban district, Legube and Santelli (2004) observe that despite awareness of existing social and integration services, the 'worst off' do systematically not enter into public support schemes. These authors underline self-exclusive behaviours among the most disadvantaged young people, whose participation risks negatively affecting their identities and self-esteem by overexposing individual deficits and marking them as 'losers'.

These corrosive effects of inequalities on participation are even amplified in formalized settings. As Lijphart (1997) puts it, the 'systematic bias [against the participation of the most vulnerable] applies with special force to the more intensive and time-consuming forms of participation' (Lijphart 1997, p.1), like campaigning, organizing meetings with local elected representatives, implementing sustainable forums of discussion inside the community and so on. Studies providing situated analyses of local participative settings have interpreted unequal participation in the light of inter-group relations and identity dynamics. In this perspective, resistance or refusal to participate may represent a way to contest specific power relations or express disagreement with decisions perceived as illegitimate. Mazeaud and Talpin (2010) interpret underprivileged pupils' boycott of participative meetings initiated by a school administration as a 'facesaving' strategy, a means to avoid confronting themselves with what they 
consider as an oppressive universe from which they feel outsiders. One can then easily imagine that such initiatives may potentially lead to additional stigmatization and, conversely, symbolic gratifications for behaviours compliant with the rules of 'the institutional game'. Despite the declared will to foster inclusion and promote opinion-giving, the very dynamics of participative action can paradoxically increase disparities between groups and reinforce mechanisms of social marginalization.

Consequently, the evaluation of a person's participation must rely on more holistic descriptions to highlight the social conditions under which one can fruitfully participate or decide not to participate. Pursuing such an ambitious research programme requires taking into consideration the agency of actors in relation to their various affiliations, acknowledging the richness and complexity of people's inscriptions in the world. This appears all the more urgent when considering the fact that disadvantaged people are, in most current public debates, more objects of social and political concern than self-producers of own discourses, and that initiatives and policies remain largely under the goodwill of other persons speaking in their name.

\section{REFRAMING SOCIAL INEQUALITIES THROUGH GENUINE PARTICIPATION}

Overcoming these limitations involves a model in which the normative views of persons can be fully considered. First of all, this requires moving beyond the epistemological breakdown between, let us say, the 'analyst' (by extension the agent in charge of implementing public policies) and the 'analysed', which denies to the latter the ability to adequately represent his/ her world and produce valid statements about his/her situation. Following pragmatist perspectives, such a breakdown would leave in the shadow the 'concern for the good that persons are moved by, and ignore the question of what is just, leaving that to the conscientious attention of researchers' (Boltanski and Thévenot 2000, p. 208). For their part, intersectional approaches have provided case studies on multiple-underprivileged and dominated groups that demonstrate the epistemological unsubstitutability of their expertise and standpoint concerning the power relations they have to deal with and the concrete implications these have in their everyday life.

In our view, the Capability Approach paves the way towards such an encompassing and requiring definition of both inequality and participation that allows integrating more dimensions and responding to most criticisms listed above. It insists that there is a strong connection between equality of opportunities and participation: in Sen's words, silence or 
absence of participation is the worst enemy of social justice and, we may add, inequality or social injustice is certainly the main obstacle impeding effective democratic participation. In such a perspective, participation and inequality are envisaged jointly. In our case, the non-inclusion of the voices of the most deprived may result in a poor public intervention when it comes to tackling inequalities and poverty affecting them; additionally, it may result in a reductionist view (a limited IBJJ) of inequality, for example, focusing on income or wealth and discarding other relevant dimensions, or adopting a short-term perspective privileging quick-fix remedies whereas the cumulation of inequalities would require more time, or acting on one single dimension and occulting the intersectional character of inequalities. By contrast, an effective participation of people, especially giving to disadvantaged persons the effective capability to voice their problems and make them count in the policymaking process, appears as a prerequisite for such an encompassing definition of inequality, which paves the way for the development of an extensive public action in this respect. Indeed, public policies should not be implemented in paternalistic ways in which other people define the beneficiaries' needs and the best ways to satisfy them, but requires the active participation of all people, whatever their social background, educational level, gender, race, age and so on. Conversely, the reduction of inequalities, be they social, economic, cultural and so on, or at the very least the neutralization of their penalizing effects, is necessary for securing equal participation to all. This entails an extensive public action against all relevant inequalities, and not simply in the field of income or education. Without such an action, the subsisting inequalities may well impede the effective participation of the most disadvantaged.

It makes then sense to conceptualize social policies as possible contributors to securing the conditions of participation. Based on the Capability Approach, one can extend liberal conceptions of citizenship which usually see the granting of specific citizenship rights, such as the right to vote, to stand for an office, free speech and so on as sufficient for securing participation in democratic deliberative exercises. In a wider conception, the ability to function as a citizen requires an 'effective access to the goods and relationships of civil society' (Anderson 1999, p. 318). This extends much beyond formal rights of participation and requires the removal of all material and symbolic obstacles that impede access to the public sphere, which can 'function well and improve public reasons only if all citizens can effectively exercise their freedom within it' (Bohman 1996, p. 110). Thus, real participation depends on a range of symbolic resources that are partly outside people's control. Identity markers like gender, race, class and so on, may impede 'a view of oneself as the legitimate source of reasons for acting' (Anderson and Honneth 2005, p. 146), affecting in turn people's 
sense of self-legitimacy to have a say when it comes to take part in a collective decision. Such an approach invites to consider sentiments of social disrespect or misrecognition as important obstacles to participation. As a consequence the 'social conditions of being accepted by others, such as the ability to appear in public without shame, and not being ascribed an outcast status' (Anderson 1999, p. 317) are equally relevant. There are also material conditions to participation, such as the 'effective access to the means of sustaining one's biological existence-food, shelter, clothing, medical care and access to the basic conditions of human agency, knowledge of one's circumstances and options, the ability to deliberate' (Anderson 1999, p. 317). The securing of a decent level of living constitutes a precondition for a person to participate in collective decision-making processes.

\section{THE ROLE OF PUBLIC ACTION IN FOSTERING PEOPLE'S CAPABILITY FOR VOICE}

In order to pave the way towards such an approach to participation, we draw on Bohman's work and suggest to use the notion of 'capability for voice', which designates the extent to which people are allowed to express their wishes and concerns in collective decision-making processes and make them count. As Salais (2009, p. 18) puts it, 'citizen participation in collective decision-making is irreplaceable. .. The fundamental reason for social criticism lies in the real value of the knowledge arising from social practice that citizens possess'. In other words, to what extent are people able and allowed to push their views when it comes to select a specific informational basis about the inequalities and deprivations affecting them? To sum up the various features mentioned in previous sections, such 'capability for voice' relies on many conditions such as:

1. The presence of cognitive resources that encompass not only access to information produced by others, but also, and even more significantly, the ability to produce one's own knowledge and information about one's specific situation. For instance, when describing the living situations of persons, if only the information produced by experts or representatives of public administrations is taken into account, this may result in a reductionist picture that will, in turn, result in a reductionist conception of public action. Indeed, these data and information risk being informed by these people's external views on which inequalities should be tackled and how this should be done. The availability of such cognitive resources often depends on the action of third persons 
that translate beneficiaries' views and perceptions in such a way to make them count.

2. The availability of political rights (for example, constitutional guarantees for participation, access to public arenas, freedom of speech and so on). In our case, the ability to create effective indirect 'voice systems' may be key, although this raises the issue of representation, that is, to what extent do representatives truly represent the viewpoints of the 'represented'.

3. The availability of material and symbolic resources, considered here as primary conversion factors of political rights into real participation. Stigma, marginalized identity, as well as material deprivation move deprived people away from arenas of public deliberation or, at least, restrain their power to make their voice count. Drawing on this argument, one can ask the following questions: What (material and symbolic) safeguards are put into place to fight against these mechanisms? To what extent are participative initiatives supported by public actors likely to supply these missing resources? As a matter of fact, such questions inevitably bring back issues of redistribution (Fraser 1997) and recognition (Honneth 1996) in the debate.

4. The 'readiness' of interlocutors - in this case representatives of public administrations, third-sector local agents and so on - to listen to the concerns expressed by disadvantaged people. In a capability perspective, lip service to people's voices would go against their capability for voice. Our concern here is with the actual influence of voice and this to a large extent depends on the readiness of institutional interlocutors and society at large to take into account this voice. The 'grammars' and codes used in the decision-making processes may well have very penalizing effects, if they do not recognize the equal validity of different ways of self-expression.

This list is far from exhaustive, it indicates some of the dimensions to be taken into account when it comes to investigate the degree of capability for voice enjoyed by people, especially by the most disadvantaged among them, and identify the main obstacles in this respect. It unambiguously shows that promoting the participation of persons requires, at the same time, empowering them to take their part and creating arenas where they are allowed to effectively voice their viewpoints and wishes. From this perspective, public action is called to open up discursive spaces for collective deliberation about the most appropriate definition (or informational basis) of inequality and the most adequate ways to tackle it. Instilling such a challenging vision in the heart of public action would create an impetus towards social change. 


\section{NOTE}

1. This chapter heavily draws on a paper published by the authors in the Swiss Journal of Social Work: Beuret, B., J.-M. Bonvin and S. Dahmen (2013),'Identifying and Tackling Inequality. A Challenge for Social Work', Revue Suisse de Travail Social, 2013, 13 (2), 9-25. We thank the editors of this journal for their permission to re-work the article for the present volume.

\section{REFERENCES}

Albrecht, Gary L. (1992), The Disability Business: Rehabilitation in America, Newbury Park, CA: Sage Publications.

Anderson, Elizabeth S. (1999), 'What Is the Point of Equality?', Ethics, 109 (2), 287-337.

Anderson, Joel H. and Axel Honneth (2005), 'Autonomy, Vulnerability, Recognition and Justice', in Joel H. Anderson and John Christman (eds), Autonomy and the Challenges to Liberalism: New Essays, Cambridge: Cambridge University Press, pp. 127-149.

Barnes, Colin (1992), 'Qualitative Research: Valuable or Irrelevant?', Disability, Handicap and Society, 7 (2), 115-124.

Barnes, Colin, Geof Mercer and Tom Shakespeare (1999), Exploring Disability: A Sociological Introduction, Cambridge: Polity Press.

Bohman, James (1996), Public Deliberation: Pluralism, Complexity, and Democracy, Cambridge: MIT Press.

Boltanski, Luc and Laurent Thévenot (2000), 'The Reality of Moral Expectations: A Sociology of Situated Judgement', Philosophical Explorations, 3 (3), 208-231.

Bourdieu, Pierre (1966), 'L'école conservatrice. Les inégalités devant l'école et devant la culture', Revue Française de Sociologie, 7 (3), 325-347.

Choo, Hae Yeon and Myra Marx Ferree (2010), 'Practicing Intersectionality in Sociological Research: A Critical Analysis of Inclusions, Interactions, and Institutions in the Study of Inequalities', Sociological Theory, 28 (2), 129-149.

Collins, Patricia Hill (1990), Black Feminist Thought: Knowledge, Consciousness, and the Politics of Empowerment, Boston: Unwin Hyman.

Dalbert, Claudia (2001), The Justice Motive as a Personal Resource: Dealing with Challenges and Critical Life Events, New York: Kluwer Academic/Plenum Publishers.

Dewey, John (1999), Liberalism and Social Action, Amherst, NY: Prometheus Books.

Dooley, David, Jonathan Fielding and Lennart Levi (1996), 'Health and Unemployment', Annual Review of Public Health, 17 (1), 449-465.

Dubet, François (2011), 'Régimes d'inégalité et injustices sociales', SociologieS, http://sociologies.revues.org/3643, accessed 12 April 2013.

Duffy, Mignon (2007), 'Doing the Dirty Work. Gender, Race, and Reproductive Labor in Historical Perspective', Gender and Society, 21 (3), 313-336.

Durkheim, Emile ([1893] 1973), De la division du travail social, Paris: PUF.

Duru-Bellat, Marie (2011), 'La face subjective des inégalités. Une convergence entre psychologie sociale et sociologie?', Sociologie, 2 (2), 185-200. 
Fraser, Nancy (1987), 'Women, Welfare and the Politics of Need Interpretation', Hypatia, 2 (1), 103-121.

Fraser, Nancy (1997), Justice Interruptus: Critical Reflections on the 'Postsocialist' Condition, New York: Routledge.

Glenn, Evelyn Nakano (2000), 'Creating a Caring Society', Contemporary Sociology, 29 (1), 84.

Glenn, Evelyn Nakano (2010), Forced to Care: Coercion and Caregiving in America, Cambridge, MA: Harvard University Press.

Graham, Hilary (2004), 'Social Determinants and Their Unequal Distribution: Clarifying Policy Understandings', Milbank Quarterly, 82 (1), 101-124.

Hahn, Harlan (1982), 'Disability and Rehabilitation Policy: Is Paternalistic Neglect Really Benign?', Public Administration Review, 42 (4), 385-389.

Hochschild, Arlie Russell (1983), The Managed Heart: Commercialization of Human Feeling, Berkeley: University of California Press.

Honneth, Axel (1996), The Struggle for Recognition: The Moral Grammar of Social Conflicts, Cambridge, MA: MIT Press.

Ibos, Caroline (2009), 'Du macrocosme au microcosme, du vaste monde à l'appartement parisien, la vie morale de la Nounou', Multitudes, 37-38 (2), $123-131$.

Ibos, Caroline (2013), 'Quand la garde d'enfants se mondialise', Plein droit, 96 (1), 7-10.

Kessler, Ronald C., J. Blake Turner and James S. House (1988), 'Effects of Unemployment on Health in a Community Survey: Main, Modifying, and Mediating Effects', Journal of Social Issues, 44 (4), 69-85.

Legube, Aude and Emmanuelle Santelli (2004), 'Paradoxes Autour de La Participation', Agora Débats/jeunesses, 38 (1), 84-96.

Levine, Donald N. (1995), 'The Organism Metaphor in Sociology', Social Research, 62 (2), 239-265.

Lijphart, Arend (1997), 'Unequal Participation: Democracy's Unresolved Dilemma', The American Political Science Review, 91 (1), 1-14.

Marmot, Michael and Richard Wilkinson (2005), Social Determinants of Health, Oxford: Oxford University Press.

Mazeaud, Alice and Julien Talpin (2010), 'Participer pour quoi faire ? Esquisse d'une sociologie de l'engagement dans les budgets participatifs', Sociologie, 1 (3), 357-374.

Oliver, Michael (1990), The Politics of Disablement: A Sociological Approach, London: Palgrave Macmillan.

Parreñas, Rhacel Salazar (2000), 'Migrant Filipina Domestic Workers and the International Division of Reproductive Labor', Gender and Society, 14 (4), 560-580.

Parsons, Talcott (1940), 'An Analytical Approach to the Theory of Social Stratification', American Journal of Sociology, 45 (6), 841-862.

Salais, Robert (2009), 'Deliberative Democracy and Its Informational Basis: What Lessons from the Capability Approach', Paper presented at the conference of the Society for the Advancement of Socio-Economics, Paris, 2009, http://halshs. archives-ouvertes.fr/halshs-00429574, accessed 18 April 2013.

Sen, Amartya (1979), 'Equality of What?', The Tanner Lecture on Human Values, Stanford University, 22 May.

Sen, Amartya (1990), 'Justice: Means versus Freedoms', Philosophy and Public Affairs, 19 (2), 111-121. 
Shakespeare, Tom and Nicholas Watson (1997), 'Defending the Social Model', Disability and Society, 12 (2), 293-300.

Shapiro, Joseph P.(1994), No Pity: People with Disabilities Forging a New Civil Rights Movement, New York: Crown Publishing Group.

Thomas, Carol (1999), Female Forms: Experiencing and Understanding Disability, Philadelphia: Open University Press.

Wolff, Jonathan and Avner de-Shalit (2007), Disadvantage, Oxford: Oxford University Press.

Zimmermann, Bénédicte (2006), 'Pragmatism and the Capability Approach. Challenges in Social Theory and Empirical Research', European Journal of Social Theory, 9 (4), 467-484.

Zinn, Maxine Baca and Bonnie Thornton Dill (1996), 'Theorizing Difference from Multiracial Feminism', Feminist Studies, 22 (2), 321-331. 